\title{
Don't Give Up on the Self Too Quickly
}

Scott N. Taylor

Babson College

Bracken, Rose, and Church (2016) call for less self- versus other research. They say that self-ratings versus non-self-ratings research (often referred to as self-other agreement research, or SOA) is not particularly helpful and that self-ratings' primary purpose is to serve as a "reflection point for individuals receiving feedback" (Bracken, Rose, \& Church, p. 785). It is true that SOA research has played a dominant role with $360^{\circ}$ feedback for many years (for a review, see Fleenor, Smither, Atwater, Braddy, \& Sturm, 2010), but the value we can draw from the self through $360^{\circ}$ feedback remains terrain largely unexplored.

Scholar and practitioner interest in SOA is understandable because SOA has been shown to predict important outcomes. For example, researchers and practitioners have frequently used SOA to predict managerial success and effectiveness (e.g., Fletcher, 1999), leader behavior and performance (e.g., Atwater \& Yammarino, 1992), and interpersonal effectiveness (e.g., Brutus, Fleenor, \& Tisak, 1999) and to distinguish between high and average performing managers (e.g., Church, 1997).

On the other hand, it is baffling to see how researchers and practitioners have become so enamored with SOA. For decades we have had compelling evidence that self-assessment, self-rating, and self-evaluation in general tend to be inflated, biased, and unreliable regarding a person's ability to assess his or her own behavior, skills, or personality traits (e.g., Dunning, 2005; Leary, 2004; Podsakoff \& Organ, 1986). Sedikides (1993) found that among the three major motivations for self-evaluation (i.e., self-assessment, self-enhancement, and self-verification), the self-enhancement motive was shown to be the most powerful determinant of the self-evaluation process. As Taylor (2014) points out, these biases call into question the accuracy and validity of using self-ratings at all given their simplistic treatment of the complex self.

Scott N. Taylor, Management Division, Babson College.

Correspondence concerning this article should be addressed to Scott N. Taylor, Management Division, Babson College, Tomasso Hall, Number 229, 231 Forest Street, Babson Park, MA 02457. E-mail: staylor@babson.edu 
Still, in reviewing the research of what SOA has predicted at the individual level, we find yet another benefit of SOA. It is not uncommon to find SOA referred to as a measure of self-awareness (e.g., Church, 1997; Fletcher \& Baldry, 2000; Wohlers \& London, 1989). The custom has been to assume that higher self-awareness equates to a smaller gap between self-ratings and others' ratings. With the use of $360^{\circ}$ feedback's SOA capability, we presumably now have an easier, less intrusive way to measure such an important leader and manager capability in self-awareness.

These two long-standing benefits from $360^{\circ}$ feedback-obtaining ratings from the self as a measure of self-awareness and SOA research-provide the springboard for future $360^{\circ}$ feedback research and practice. But to enter possible new frontiers, we must not give up on the self too quickly.

Classical theories of individual self-awareness collectively define selfawareness as more than just how a person sees him- or herself (captured to some degree with self-ratings). Instead, self-awareness is defined as having two primary components: (a) how people see themselves and the process by which people make assessments about themselves and (b) the ability to detect how they are perceived by others. Accordingly, this two-component definition assumes that individuals must have an understanding of themselves, but they must also have an understanding of and appreciation for others' perceptions of them (Baumeister, 2005; Hall, 2004).

Surprisingly, $360^{\circ}$ feedback practitioners and researchers alike have largely ignored the second component of self-awareness, in spite of its importance to being socially aware and to leadership (Taylor, 2010). Since the 1950s, researchers may have assumed that the two components of self-awareness were the same when operationalized. Specifically, studies from Reeder, Donohue, and Biblarz (1960); Quarantelli and Cooper (1966); Shrauger and Schoeneman (1979); and many others had participants predict how people viewed them and then compared those predicted ratings with the actual ratings of others. Results primarily showed that peoples' selfratings and how they predicted others would see them were nearly identical but not very close to how others actually saw them. Interestingly, these studies were not assessing behaviors commonly assessed by $360^{\circ}$ feedback but instead were largely focused on personality traits and mannerisms of young college students.

There are important reasons why we should care about the second component of self-awareness as it relates to $360^{\circ}$ feedback. First, self-ratings of behavior appear to not be the same as predicted ratings of behavior (e.g., Sturm, Taylor, Atwater, \& Braddy, 2014; Taylor \& Hood, 2011). This is likely because self-ratings access the first component of self-awareness, and predicted ratings access the second component. In other words, predicted ratings are accessing a different part of the self than self-ratings. By 
predicted ratings, I mean asking participants of $360^{\circ}$ feedback to predict as accurately as possible how others rated them (i.e., their manager, peers, and/or direct reports). This can be done by asking participants to select a rater group they are most interested in predicting, by asking participants to predict an assigned rater group (e.g., their manager), or by randomly assigning a rater group for participants to predict. Participants then retake the $360^{\circ}$ survey and try to predict how the assigned group or person rated them.

Although still early as a new frontier in $360^{\circ}$ feedback research, one study has shown that prediction-other ratings agreement with self- and direct reports' ratings was a stronger predictor of performance than SOA (Taylor, Wang, \& Zhan, 2012). With the collection of predicted ratings, $360^{\circ}$ feedback can become an important tool to better understanding the second component of self-awareness.

From a practical perspective, I have found that most $360^{\circ}$ feedback participants like the challenge of trying to guess as accurately as possible how they were rated by others and like to receive a feedback report that allows them to compare how they see themselves (i.e., self-ratings), how others see them (i.e., others' ratings), and how they thought others would see them (predicted ratings). I have found that it is important to limit the number of rater groups participants are asked to predict. In our research, we have limited this to two randomly assigned rater groups or to just the participants' manager or direct reports (depending on the research study). In practice, I have mostly allowed the participants to select the rater group they are most interested in predicting. I have found most participants choose to predict either their manager's or their direct reports' ratings.

Second, there is a more important reason we should not be quick to cast aside exploring predicted ratings that come from the self versus ratings that come from others using $360^{\circ}$ feedback. Recent research shows that men and women predict the ratings of others differently (e.g., Sturm et al., 2014; Taylor \& Hood, 2011). This is important in today's world, where we see greater numbers of women assuming managerial and leadership positions and yet facing obstacles along their way, such as being underpaid compared with men and having an inability to reach the upper echelons of leadership compared with men (e.g., women on boards of governance). Predictionother agreement research shows that women leaders predict others' ratings of them to be lower than are men's predictions, which has important implications when it comes to leadership. Such implications can include decreases in self-efficacy/confidence, lack of advancement, decreased assertiveness, lower performance, gender inequality, or negative emotional responses (Taylor, Sturm, Atwater, \& Braddy, 2016). With the collection of predicted ratings, $360^{\circ}$ feedback can become an important tool both in research and 
in practice to further our understanding of important gender differences in organizations.

Third, Taylor and Bright (2011) propose that there is a benefit in asking $360^{\circ}$ feedback participants to predict how others rate them because predicted ratings may foster greater openness on the part of the participant. Predicted ratings may defuse some of the defensiveness triggered by the frequent discrepancy between self-ratings and the ratings of others. Too often, $360^{\circ}$ feedback participants feel like they must create a narrative to explain or even justify why they do not see themselves the same way others see them. The collection of predicted ratings can broaden the $360^{\circ}$ feedback development discussion by moving beyond self-versus-other defensiveness to questions like, "How aware am I as to how others experience me?" For example, for those whose self-ratings are higher than the ratings of others and who are yet unaware of the negative implications their overrating is having on others, predicted ratings are especially beneficial in moving the conversation away from defending self-ratings to exploring why these participants were not able to predict how others rated them.

As tempting as it may be to move away from more self- versus other research and decrease the focus on the self when it comes to $360^{\circ}$ feedback, to date, we have not taken advantage of the complex self. We have used a limited definition when defining self-awareness with $360^{\circ}$ feedback. It is time we broaden our definition to include the second component of self-awareness and begin exploring the value of predicted ratings. Doing so will help us explore new directions in $360^{\circ}$ feedback research and practice with important implications for both.

\section{References}

Atwater, L. E., \& Yammarino, F. J. (1992). Does self-other agreement on leadership perceptions moderate the validity of leadership and performance predictions? Personnel Psychology, 45, 141-164.

Baumeister, R. F. (2005). The cultural animal: Human nature, meaning, and social life. New York, NY: Oxford University Press.

Bracken, D. W., Rose, D. S., \& Church, A. H. (2016). The evolution and devolution of $360^{\circ}$ feedback. Industrial and Organizational Psychology: Perspectives on Science and Practice, 9(4), 761-794.

Brutus, S., Fleenor, J. W., \& Tisak, J. (1999). Exploring the link between rating congruence and managerial effectiveness. Canadian Journal of Administrative Sciences, 16, 308-322.

Church, A. H. (1997). Managerial self-awareness in high-performing individuals in organizations. Journal of Applied Psychology, 82, 281-292.

Dunning, D. (2005). Self-insight: Roadblocks and detours on the path to knowing thyself. New York, NY: Psychology Press.

Fleenor, J. W., Smither, J. W., Atwater, L. E., Braddy, P. W., \& Sturm, R. E. (2010). Self-other rating agreement in leadership: A review. Leadership Quarterly, 21, 1005-1034.

Fletcher, C. (1999). The implications of research on gender differences in self-assessment and 360 degree appraisal. Human Resource Management Journal, 9(1), 39-46.

Fletcher, C., \& Baldry, C. (2000). A study of individual differences and self-awareness in the context of multi-source feedback. Journal of Occupational and Organizational Psychology, 73, 303-319. 
Hall, D. T. (2004). Self-awareness, identity, and leader development. In D. V. Day, S. J. Zacarro, \& S. M. Halpin (Eds.), Leader development for transforming organizations: Growing leaders for tomorrow (pp. 153-176). Mahwah, NJ: Erlbaum.

Leary, M. R. (2004). The curse of the self: Self-awareness, egotism, and the quality of human life. New York, NY: Oxford University Press.

Podsakoff, P. M., \& Organ, D. W. (1986). Self-reports in organizational research: Problems and prospects. Journal of Management, 12, 531-544.

Quarantelli, E. L., \& Cooper, J. (1966). Self-conceptions and others: A further test of Meadian hypotheses. Sociological Quarterly, 7, 281-297.

Reeder, L. G., Donohue, G. A., \& Biblarz, A. (1960). Conceptions of self and others. American Journal of Sociology, 66, 153-159.

Sedikides, C. (1993). Assessment, enhancement, and verification determinants of the self-evaluation process. Journal of Personality and Social Psychology, 65, 317-338.

Shrauger, J. S., \& Schoeneman, T. J. (1979). Symbolic interactionist view of self-concept: Through the looking glass darkly. Psychological Bulletin, 86, 549-573.

Sturm, R. E., Taylor, S. N., Atwater, L. E., \& Braddy, P. W. (2014). Leader self-awareness: An examination and implications for women leaders. Journal of Organizational Behavior, 35, 657-677.

Taylor, S. N. (2010). Redefining leader self-awareness by integrating the second component of selfawareness. Journal of Leadership Studies, 3(4), 57-68.

Taylor, S. N. (2014). Student self-assessment and multisource feedback assessment: Exploring benefits, limitations, and remedies. Journal of Management Education, 38(3), 360-384.

Taylor, S. N., \& Bright, D. S. (2011). Exploring conditions for openness in multisource feedback assessment. Journal of Applied Behavioral Science, 47, 432-460.

Taylor, S. N., \& Hood, J. (2011). It may not be what you think: Gender differences in predicting emotional and social competence. Human Relations, 64(5), 627-652.

Taylor, S. N., Sturm, R. E., Atwater, L. E., \& Braddy, P. W. (2016). Underestimating one's leadership impact: Are women leaders more susceptible? Organizational Dynamics, 45, 132-138.

Taylor, S. N., Wang, M., \& Zhan, Y. (2012). Going beyond self-other rating agreement: Comparing two components of self-awareness using multisource feedback assessment. Journal of Leadership Studies 6(2), 6-31.

Wohlers, A. J., \& London, M. (1989). Ratings of managerial characteristics: Evaluation difficultly, coworker agreement, and self-awareness. Personnel Psychology, 42, 235-261. 